\title{
EL CONVENIO ARBITRAL EN EL DERECHO PERUANO
}

Frank García Ascencios

\section{Resumen}

El presente artículo define al arbitraje como un acto jurídico, el cual funciona como un mecanismo para la solución de conflictos entre las partes. Cabe resaltar, que tiene su origen en el convenio arbitral, el cual nace en virtud a la autonomía privada de las partes. Asimismo, se detalla las formalidades y los principios que rigen al arbitraje, tales como "Competencia de la competencia", "Separabilidad del convenio" y "Principio de única instancia". Finalmente, se realizará una breve reflexión acerca de los inconvenientes que podrían presentarse en el ejercicio de esta figura jurídica.

\section{Summary}

This article defines the arbitration as a legal act, which functions as a mechanism for resolving disputes between the parties. It should be noted. that has its origin in the arbitration agreement, which comes under the private autonomy of the parties. It also explains the formalities and the governance principies of the arbitration, such as "competition ofcompetition», "severahility of agreement» and "principie of single instance.» Finally, malee a brief reflection on tlie problems that could arise in the exercise of this legal mechanism.

\section{Sommaire}

Cet article définie l'arhitrage comme un acte juridique, qui fonctionne comme un mécanisme de réglement des dijférends entre les parties. II est á noter. qui a son origine dans la convention d 'arbitrage, qui releve de I 'autonomie privée des parties. II détaille également les formal;tés et les principes qui régissent l'arhitrage, tels que «la concurrence de la concurrence», "autonomié de la convention» et «principe d'instance unique.»En fin, se fasse une breve reflexión sur les prohlémes qui pourraient surgir dans I 'exercice de ce mécanisme juridique. 


\section{INTRODUCCIÓN}

El arbitraje es un mecanismo heterocompositivo, garantista y esencialmente voluntario, donde las partes someten una o más controversias sobre materias de libre disposición, con el objeto de que sean resueltas por un tercero o terceros, denominados árbitro o tribunal arbitral, los cuales poseen independencia e imparcialidad.

El arbitraje tiene su origen en el convenio arbitral, de ahí que sea una figura jurídica de imprescindible estudio en el Derecho de arbitraje. En las próximas líneas, se efectúa algunos comentarios sobre esta. Además de analizar la vigente regulación que le otorga el Decreto Legislativo 1071 (en adelante "DLA").

\section{IL CONCEPTO}

El convenio arbitral es el acuerdo entre laspartes para resolver sus controversias a través de un proceso arbitral. En términos técnicos, dicho acuerdo es un acto jurídico impropio, pues lo que se busca es la resolución de conflictos dentro de un proceso garantista, donde se actúe acorde a la tutela procesal efectiva y, por ello, con debido proceso. Por tal motivo, se afirma que el convenio arbitral provoca un doble efecto $^{1}$ : uno positivo y otro negativo. Genera un efecto positivo, pues las controversias serán resueltas en un proceso arbitral, donde las partes deberán cumplir con lo laudado. Asimismo, produce un efecto negativo, ya que otros órganos están impedidos de solucionar las controversias que mediante convenio arbitral se ha encargado de manera exclusiva a los árbitros.

El convenio arbitral nace de la libertad que tienen los seres humanos para regular sus relaciones jurídicas. Por ende, la autonomía privada es el fundamento del arbitraje. ${ }^{2}$ Así, el DLA ha optado por conceptualizar en su artículo $13^{03}$ al convenio arbitral como:

"(...) un acuerdo por el que las partes deciden someter a arbitraje todas las controversias o ciertas controversias que hayan surgido o puedan surgir entre ellas respecto de una determinada relación jurídica contractual o de otra naturaleza $(\ldots)^{\prime \prime}$.

Asimismo, se debe indicar que no toda controversia puede ser llevada a la vía arbitral, pues el DLA en su artículo $2^{\circ}$ inc. 1 señala que solo "pueden someterse a arbitraje las controversias sobre materias de libre disposición conforme a Derecho, asi como aquellas que la ley o los tratados o acuerdos internacionales autoricen "J tituto Vasco de Derecho Procesal. 2009, p. 69.

MATHEUS LÓPEZ, Carlos. La independencia e imparcialidad del árbitro. San Sebastián: InsEl considerar al convenio arbitral como fundamento del arbitraje, de ninguna manera quiere decir, que con el convenio se dé inicio al arbitraje, ya que según el artículo $33^{\circ}$ del DLA salvo acuerdo distinto entre las partes este se iniciará "en la fecha de recepción de la solicitud para someter una controversia a arbitraje". Asimismo, el inicio del arbitraje no debe confundirse con el momento en el cual los árbitros están válidamente instalados, pues el articulo $27^{\circ}$, inciso 2 del DLA dice que se tendrá un tribunal instalado "una vez producida la aceptación del árbitro único o del último de los árbitros". 3

El artículo 13" del DLA sigue la línea del artículo $7^{\circ}$ de la Ley Modelo de la CNUDMI/UNCI TRAL. $4 \quad$ La regulación de esta norma es adecuada, pues no elabora una lista cerrada o taxativa (numerus casos (numerus apertus). 
En ese sentido, las personas que se sometan a la vía arbitral lo harán respecto de materias de libre disposición, es decir, donde sea posible pactarse una vía resolutiva ajena a la judicial, ya que son de naturaleza privada. Entonces, se restringen las materias de origen público, reservadas a la competencia de los jueces del órgano estatal de justicia ${ }^{5}$; sin embargo, en la práctica resulta complicado afirmar qué materias son de libre disposición, pues estas ya no solo se enmarcan en los clásicos Derecho Civil Patrimonial" y Derecho Comercial ${ }^{7}$. En la actualidad, materias impensadas son arbitrables, tales como el arbitraje laboral* y el arbitraje de salud $^{l}$, por lo que el mandato de ley, tratados o acuerdos internacionales son imprescindibles para determinar qué controversias son arbitrables y dejar de lado el tradicional análisis de la libre disposición.

Así como las partes pueden elegir la vía arbitral, también ellas pueden renunciar al arbitraje, sea de manera expresa o tácita. Por ello, el artículo $18^{\circ}$ del DLA dice que "es expresa cuando consta en un documento suscrito por las partes, en documentos separados, mediante intercambio de documentos o mediante cualquier otro medio de comunicación que deje constancia inequívoca de este acuerdo. Es tácita cuando no se invoca la excepción de convenio arbitral en el plazo correspondiente, solo respecto de las materias demandadas judicialmente ",

\section{FORMALIDAD}

Con respecto a la formalidad que debe tener el convenio arbitral, el DLA en su artículo $13^{\circ}$ inc. 2 señala que "deberá constar por escrito ", pero sin indicar la frase "bajo sanción de nulidad". Por ende, debe entenderse que la forma exigida (forma escrita), simplemente es un medio de prueba (adprobationem) que sirve para acreditar la existencia del convenio"1. Entonces, la forma escrita no resulta imprescindible para la existencia del convenio, pues solo será una prueba que acredite la voluntad de las partes de ir a un proceso arbitral.

$\begin{array}{ll}5 & \text { Por ejemplo, en materia penal. } \\ 6 & \text { Hoy trascienden las materias civiles como nulidades, anulahilidades, resoluciones, recisiones, }\end{array}$ desalojos, ejecución de garantías inmobiliarias y mobiliarias, e indemnizaciones

Asimismo, trascienden a las materias comerciales. Según la Ley Modelo de CNUDMI/UNCITRAL "debe darse una interpretación amplia a la expresión "comercial" para que abarque las cuestiones que se plantean en todas las relaciones de índole comercial, contractuales o no. Las relaciones de índole comercial comprenden las operaciones siguientes, sin limitarse a ellas: cualquier operación comercial de suministro o intercambio de bienes o servicios, acuerdo de distribución, representación o mandato comercial, transferencia de créditos para su cobro ("factoring"), arrendamiento de bienes de equipo con opción de compra ("leasing") construcción de obras, consultaría, ingeniería, concesión de licencias, inversión, financiación, banca, seguros, acuerdo o concesión de explotación, asociaciones de empresas y otras formas de cooperación industrial o comercial, transporte de mercancías o de pasajeros por vía aérea, marítima, férrea o por carretera".

8 Decreto Supremo 010-2003 (Texto único ordenado de la Ley de Relaciones Colecticas de Trabajo).-Artículo $61^{\circ}$ : "Si no se hubiese llegado a un acuerdo en negociación directa o en conciliación, de haberla solicitado los trabajadores, podrán las parles someter el diferendo a arbitraje ",

9 Decreto Supremo No 009-97 (Reglamento de la Ley de Modernización de la Seguridad Social en Salud). Articulo 91": "La sola solicitud de organización y funcionamiento de una EPS, implica el sometimiento de ésta al reglamento de arbitraje y solución de controversias que diclara la SEPS.

Las Entidades Empleadoras, el IPSSy los afiliados a una EPS o que reciban prestaciones de salud a través de servicios propios de su empleador, quedan igualmente sometidas al reglamento de arbitraje y solución de controversias referido en el párrafo anterior.

10 Afirmación que es coherente con el Código Civil, artículo $144^{\circ}$, donde se indica que "cuando la ley impone una forma y no sanciona con nulidad su inobservancia, constituye solo un medio de prueba de la existencia del acto ". 
La denominación "escrito" que acoge el DLA. en plena concordancia con el artículo $7^{\circ}$ de la Ley Modelo de la CNUDMI/UNCITRAL, debe ser entendido en términos flexibles, ya que no necesariamente debe llevarnos a imaginar la suscripción del convenio en un documento, sino que según el artículo $13^{\circ}$ del DLA

"(...) 3. Se entenderá que el convenio arbitral es escrito cuando quede constancia de su contenido en cualquier forma, ya sea que el acuerdo de arbitraje o contrato se haya concertado mediante la ejecución de ciertos actos o por cualquier otro medio. 4. Se entenderá que el convenio arbitral consta por escrito cuando se cursa una comunicación electrónica y la información en ella consignada es accesible para su ulterior consulta. Por "comunicación electrónica" se entenderá toda comunicación que las partes hagan por medio de mensajes de datos. Por "mensaje de datos" se entenderá la información generada, enviada, recibida o archivada por medios electrónicos, magnéticos, ópticos o similares, como pudieran ser, entre otros, el intercambio electrónico de datos, el correo electrónico, el telegrama, el télex o el telefax. 5. Se entenderá además que el convenio arbitral es escrito cuando esté consignado en un intercambio de escritos de demanda y contestación en los que la existencia de un acuerdo sea afirmada por una parte, sin ser negada por la otra. 6 . La referencia hecha en un contrato a un documento que contenga una cláusula de arbitraje constituye un convenio arbitral por escrito, siempre que dicha referencia implique que esa cláusula forma parte del contrato/...)", (subrayado nuestro)

El término "escrito" del DLA desfigura la definición que se le da en el Diccionario de la Real Academia Española, donde se le conceptualiza como una "carta, documento o cualquier papel manuscrito, mecanografiado o impreso" ${ }^{11}$.En esa línea, ha de plantearse la interrogante sobre el motivo por el cual se opta por el término escrito, cuando en realidad no se halla stricto sensu ante un "convenio arbitral escrito". La respuesta se encuentra en la Convención de Nueva York de 1958, artículo II, numeral 1, que dice:

“(...) cada lino de los Estados contratantes reconocerá el acuerdo por escrito conforme al cual las partes se obliguen a someter a arbitraje todas las diferencias o ciertas diferencias que hayan surgido o puedan surgir entre ellas respecto a una determinada relación jurídica, contractual o no contractual, concerniente a un asunto que pueda ser resuelto por arbitraje

Por ello, producto de la adhesión peruana a esta convención y en concordancia con Ley Modelo de la CNUDMI/UNCITRAL ${ }^{12}$ es que se justifica el término "escrito" en el DLA. Así. Redfem, et. al. afirman que "la mayor parte de las legislaciones modernas en materia de arbitraje intentan definir en la forma más amplia

11 Real Academia Española. Diccionario de la lengua española. [CD-rom]. Madrid. 2001.

12 La Ley Modelo de la CNUDMI/UNCITRAL en su articulo $7^{\circ}$ inc. 3 opta por la formalidad ••escrita", pues según Perales Viscosillas "el problema... reside en el deseo del Grupo de Trabajo de no separarse del concepto de escrito del CNY (Convención de Nueva York), pero al mismo tiempo la necesidad de superar un estricto lenguaje y sobre todo interpretación práctica. De ahí la solución artificial que se adopta enmascarando a otras formas de perfección del convenio arbitral... bajo el concepto de escrito". (PERALES VISCOSILLAS, Pilar. "¿Forma "escrita" del convenio arbitral?: nuevas disposiciones de la CNUDMI". Athina 3. Grijley. 2007, p. 213). 
posible los requisitos que deben reunirse para que se considere que existe un (convenio arbitral) 'escrito'"'13.

Por otra parte, respecto de la formalización del convenio arbitral escrito, se debe indicar que la doctrina ${ }^{14}$ elabora una clasificación que distingue tres tipos de modalidades en que se puede "formalizar" un convenio arbitral: convenio arbitra! por referencia, convenio arbitral unidocumental y convenio arbitral adhesivo. En la primera modalidad, el convenio no está en el contrato principal, encontrándose en otro documento donde se refiere al contrato. De ahí que, el convenio se aplique para llevar a vía arbitral las controversias que se deriven del contrato principal. En la segunda modalidad, el convenio está en el contrato principal. Por último, en la tercera modalidad, el convenio no es producto de una negociación, sino que al adherirse a un contrato, se acepta las cláusulas impuestas por una de las partes, incluida la cláusula que contiene al convenio arbitral.

No se acepta esta tesis consistente en elaborar una clasificación de las distintas modalidades en que se puede formalizar un convenio arbitral, ya que se centra en stricto sensu en un convenio escrito que considera dicho término como "escritura en un documento". Así, se deja de lado lo realmente importante: la voluntad de las partes de ir a un proceso arbitral, la cual -como se ha mencionado- trasciende a un simple documento.

\section{V. PRINCIPIOS DEL ARBITRAJE Y DEL CONVENIO ARBITRAL: "COMPETENCIA DE LA COMPETENCIA". "SEPARABILIDAD DEL CONVENIO"Y "PRINCIPIO DE ÚNICA INSTANCIA"}

La celebración del convenio arbitral refleja la intención de someter la resolución de controversias a la competencia de los árbitros. Se deriva, entonces, que las partes encargan la solución de sus conflictos de manera exclusiva a los árbitros, siendo ellos los únicos competentes para emitir una decisión final sobre el tema; sin embargo, a pesar de haber celebrado un convenio, con frecuencia las partes han buscado dilatar o evadir el arbitraje e interponen todo tipo de acciones ante los órganos administrativos o frente al órgano estatal de justicia ${ }^{15}$.

En tal sentido, frente a esta mala práctica de las partes, el Tribunal Constitucional en el caso Cantuarias Salaverry:

"(...) considera y reitera la protección de la jurisdicción arbitral, en el ámbito de sus competencias, por el principio de "no interferencia" referido en el inciso 2) del artículo constitucional antes citado, que prevé que ni nguna autoridad puede avocarse a causas pendientes ante el órgano jurisdiccional, ni interferir en el ejercicio de sus funciones. Los tribunales arbitrales, por consiguiente, dentro del ámbito de su competencia, se encuentran facultados 
para desestimar cualquier intervención y/o injerencia de terceros -incluida autoridades administrativas $\mathrm{y} / \mathrm{o}$ judiciales- destinada a avocarse a materias sometidas a arbitraje, en mérito a la existencia de un acuerdo arbitral y la decisión voluntaria de las partes $(\ldots)^{116}$.

Sobre ello, es convicción de esta investigación considerar que la jurisdicción arbitral no es el fundamento para la no intervención en el arbitraje, sino que es producto del convenio arbitral, es decir, de la voluntad de las partes para que los árbitros resuelvan de forma exclusiva sus controversias. Las mismas partes deciden que los árbitros serán los únicos competentes para pronunciarse sobre el fondo del caso y restringen todo tipo de interferencia por parte de otros órganos, a fin de evitar que se afecte el proceso arbitral ${ }^{17}$.

En esa misma línea, con el fin de consolidar la regla que "se encuentra prohibido todo tipo de intervenciones que afecten la competencia de los árbitros para seguir con el proceso arbitral", el DLA en su artículo $3^{\circ}$ regula lo siguiente:

"1. En los asuntos que se rijan por este Decreto Legislativo no intervendrá la autoridad judicial, salvo en los casos en que esta norma así lo disponga.

2. El tribunal arbitral tiene plena independencia y no está sometido a orden, disposición o autoridad que menoscabe sus atribuciones.

3. El tribunal arbitral tiene plenas atribuciones para iniciar y continuar con el trámite de las actuaciones arbitrales, decidir acerca de su propia competencia y dictar el laudo.

4. Ninguna actuación ni mandato fuera de las actuaciones arbitrales podrá

dejar sin efecto las decisiones del tribunal arbitral, a excepción del control judicial posterior mediante el recurso de anulación del laudo contemplado en este Decreto Legislativo. Cualquier intervención judicial distinta, dirigida a ejercer un control de las funciones de los árbitros o a interferir en las actuaciones arbitrales antes del laudo, está sujeta a responsabilidad".

Por consiguiente, se ha restringido la intervención administrativa o judicial cuando se haya celebrado un convenio arbitral. El Tribunal Constitucional y el DLA de forma acertada prohíben todo tipo de acción que busque dilatar o evadir el arbitraje, solo procediendo el recurso de anulación de manera posterior a ia emisión del laudo para la parte que considera se presenta alguno de los supuestos del artículo $63^{\circ}$ y de la Duodécima Disposición Complementaria del DLA.

Dos principios fundamentales que han consolidado la premisa de evitar la intervención judicial y/o administrativa en el curso del proceso arbitral han sido la "Competencia de la Competencia " y la "Separabilidad del Convenio Arbitral ", principios que se han convertido en piezas fundamentales para el fortalecimiento del arbitraje. 


\subsection{Competencia de la Competencia}

Antes de explicar que postula este principio, se debe diferenciarlo del término alemán Kompetenz-Kompetenz, el cual en el ambiente jurídico nacional ha sido considerado como sinónimo de Competencia de la competencia. Sobre ello, Matheus López dice que:

"(...) no es muy afortunada dado que, en la terminología jurídica alemana, la expresión posee un sentido diferente del que se maneja en la literatura internacional, implicando el principio Kompetenz-Kompetenz que los árbitros tienen el poder de juzgar en última instancia y sin control judicial ninguno, su competencia $(\ldots)^{\prime \prime \prime *}$.

En consecuencia, la terminología Kompetenz-Kompetenz es erróneamente utilizada en el medio jurídico ${ }^{19}$, ya que en el sistema peruano sí existe un control judicial posterior por parte del Poder Judicial. En esa línea, es claro que el sistema nacional no se adhiere a otros modelos como el considerar que el árbitro resuelve su competencia sin posibilidades de control ex post por el órgano estatal de justicia (conocido como "kompetenz-kompeienz "), o que la determinación sobre la competencia sea materia de decisión exclusiva por parte del Poder Judicial.

Hecha la precisión, ha de desarrollarse el principio Competencia de la competencia, el cual postula que los árbitros serán los únicos legitimados para decidir sobre su competencia. En otras palabras, ellos se pronunciarán sobre si en verdad existe o no un convenio arbitral que refleje una manifiesta voluntad de las partes para acudir a un proceso arbitral. Asimismo, de ser el caso, deberán analizar si en el convenio arbitral existen patologías que lo lleven a ser nulo o anulable o ineficaz o caduco. Entonces, si es que se confirma alguna de estas patologías, los árbitros no gozarán de competencia para resolver las controversias de las partes. Este principio es trascendental para el desarrollo del arbitraje, ya que busca evitar que la parte que no desea someterse a la vía arbitral dilate o evada el proceso y acuda de forma innecesaria al Poder Judicial con la evidente finalidad de que los jueces estatales obstaculicen el arbitraje.

Según Gaillard este principio "no es neutral. Está destinado, específicamente, a proteger el arbitraje. Al promover este modo de resolución de conflictos, el cual se ha convertido en un modo normal de resolución de controversias en el comercio internacional, los legisladores contemporáneos no ignoran su fragilidad. Esta se debe al hecho de que la competencia de los árbitros reposa únicamente en la voluntad de las partes. Resulta por lo tanto más fácil sabotear un arbitraje, aunque solo sea utilizando argumentos de pura lógica, como aquellos que estiman que los árbitros no están facultados para pronunciarse sobre ningún punto mientras su competencia no esté establecida, que objetar la competencia de un juez estatal. Es por ello que:

"(...) el derecho del arbitraje encontró necesario otorgar a los árbitros prioridad para pronunciarse sobre su competencia $(\ldots)^{\prime \prime 2}$.

18 MATHEUS LÓPEZ, Carlos. La independencia e imparcialidad del árbitro. Ob. Cit., p. 69.

19 Afirmación que incluye al Tribunal Constitucional, el cual en el caso Cantuarias Salaverry, en su fundamento 13, hace referencia a la terminología alemana kompetenz-kompetenz, para explicar que los árbitros resuelven su competencia, pero que cabe el recurso de anulación de forma posterior (ex post). El Tribunal debió utilizar la denominación "Competencia de la competencia", ya que el modelo peruano admite el control improcedendo de lo resuelto por los árbitros.

20 GAILLARD, Emmanuel. Teoría jurídica del arbitraje internacional. Asunción: CEDEP. 2010, pp. $100-101$.

athina 
En ese sentido, debe indicarse que la parte que no esté conforme con la determinación de competencia emitida por los árbitros tiene la opción de acudir a la juris dicción, a fin de que por medio del recurso de anulación se determine la competencia del tribunal, pero ello después de emitido el laudo, ya que siempre se tiene como finalidad no dilatar o evadir el proceso arbitral. Por consiguiente, la anulación permite no dejar en indefensión a la parte que considere no existir competencia de los árbitros.

El principio Competencia de la competencia goza de pleno reconocimiento en el DLA, el cual en su artículo $3^{\circ}$ inc. 3 expresa que:

"(•••) el tribunal arbitral tiene plenas atribuciones para iniciar y continuar con el trámite de las actuaciones arbitrales, decidir acerca de su propia competencia y dictar el laudo (...)".

Asimismo, el artículo $41^{\circ}$ dice:

"(...) el tribunal arbitral es el único competente para decidir sobre su propia competencia, incluso sobre las excepciones u objeciones al arbitraje relativas a la inexistencia, nulidad, anulabilidad, invalidez o ineficacia del convenio arbitral o por no estar pactado el arbitraje para resolver la materia controvertida o cualquiera otras cuya estimación impida entrar en el fondo de la controversia (.

De igual manera, la Ley Modelo de la CNUDMI/UNC1TRAL recoge este principio en su artículo $16^{\circ}$ inc. 1 , al decir que:

"(...) el tribunal arbitral estará facultado para decidir acerca de su propia competencia, incluso sobre las excepciones relativas a la existencia o a la validez del acuerdo de arbitraje(...)".

Entonces, el tribunal arbitral puede decidir sobre su competencia como a) cuestión previa o b)en el trascurso del proceso arbitral. Si resuelve como cuestión previa, primero evaluará su competencia para luego seguir con el arbitraje. En cambio, si decide determinarla en el transcurso del proceso, la resolverá durante el proceso o en el mismo laudo en plena concordancia con la Ley Modelo de la CNUDMI/ UNCITRAL, la cual en su artículo $8^{\circ}$ inc. 2 , en referencia a si la parte plantea una excepción por alguna patología en el convenio arbitral, señala que:

"(...) se podrá, no obstante, iniciar o proseguir las actuaciones arbitrales y dictar un laudo mientras la cuestión esté pendiente ante el tribunal $(\ldots)^{\prime \prime}$.

Esta norma permite a los árbitros decidir sobre su competencia en el momento que ellos crean adecuado, pero esto no puede llevar a abusos, ya que si es evidente que el convenio tiene alguna patología trascendental que provoque que el tribunal no tenga competencia, entonces los árbitros deberán resolver sobre su competencia como cuestión previa. Por ello, si se les observa un mal comportamiento, podrán ser responsables civilmente si estamos ante un arbitraje adhoc. Asimismo, si se halla frente un arbitraje institucional, entonces la institución también tendrá responsabilidad. 


\subsection{Separabilidad del Convenio arbitral}

Este principio postula considerar a la cláusula que contiene el convenio arbitral como distinta a las otras que se encuentran en el contrato. En tal sentido, si las otras clausulas o el mismo contrato son declarados inválidos, esto no afectará al convenio, pues este es autosuficiente, es decir, tiene validez por sí mismo. Asimismo, este principio también es fundamental para la consolidación del arbitraje, pues busca que las partes no intenten dilatar o evadir el arbitraje bajo el argumento que el contrato es nulo o anulable o ineficaz o caduco.

En adición a lo anterior, el principio de Separabilidad del convenio arbitral goza de reconocimiento en el DLA, el cual en su artículo $41^{\circ}$ inc. 2, afirma que:

"(...) el convenio arbitral que forme parte de un contrato se considerará como un acuerdo independiente de las demás estipulaciones del mismo. La inexistencia, nulidad, anulabilidad, invalidez o ineficacia de un contrato que contenga un convenio arbitral, no implica necesariamente la inexistencia, nulidad, anulabilidad, invalidez o ineficacia de este. En consecuencia, el tribunal arbitral podrá decidir sobre la controversia sometida a su conocimiento, la que podrá versar, incluso, sobre la inexistencia, nulidad, anulabilidad, invalidez o ineficacia del contrato que contiene un convenio arbitral(...)".

Asimismo, la Ley Modelo de la CNUDMI/ UNCITRAL en la segunda parte del artículo $16^{\circ}$ inc. 1 , reconoce el principio de Separabilidad del convenio arbitral cuando dice:

"(...) una cláusula compromisoria (en nuestra legislación 'convenio arbitral') que forme parte de un contrato se considerará como un acuerdo independiente de las demás estipulaciones del contrato. La decisión del tribunal arbitral de que el contrato es nulo no entrañará ipso jure la nulidad de la cláusula compromisoria $(\ldots)^{\prime \prime}$.

En síntesis, como señala Vidal Ramírez,

"(...) el convenio arbitral... solo está supeditado a la controversia que debe ser solucionada $y$, por eso. por su principalidad, no le es aplicable la máxima romana accesorium sequilar suum principale, pues, en nuestra opinión, subsiste aun si el documento que lo contiene es declarado nulo, o el contrato al que se ha insertado se le resuelve o se le rescinde (...)

En consecuencia, tanto el principio de Competencia de la competencia como el de Separabilidad del convenio arbitral han permitido que el proceso arbitral se desarrolle con normalidad, evitando cualquier tipo de interferencia por parte de otros sujetos que no tengan la calidad de árbitros. En ese sentido, tras la trascendencia de estos principios recogidos en los artículos $3^{\circ}$ y $41^{\circ}$ del DLA y de parte del fundamento 12 de la resolución del Tribunal Constitucional en el caso Cantuarias Salaverry. se considera que en la actualidad no existe mayor problema en determinar que los árbitros son los únicos que podrán decidir sobre su competencia, de cualquier cuestionamiento que 
se presente en el proceso y los que resolverán las controversias que las partes han sometido a su conocimiento. Por ello, resultará difícil la interferencia administrativa y/o judicial que busque dilatar o evitar un proceso arbitral.

\subsection{Principio de Unica instancia}

Como ya se ha expresado, el problema del arbitraje ya no radica en la intervención judicial en el proceso arbitral, en donde se buscaba que el Poder Judicial negara la competencia de los árbitros de resolver las controversias jurídicas de las partes. En la actualidad, el real problema surge luego de la emisión del laudo, pues la parte a la cual no beneficia la decisión final utiliza el recurso de anulación y el proceso constitucional de amparo con el objeto de buscar de cualquier forma su declaratoria de nulidad.

La maliciosa conducta de la parte vencida no puede llevar a obviar la existencia del convenio arbitral, por lo cual se acordó libremente someterse a la competencia exclusiva de los árbitros con el fin de resolver las controversias que acogen todos los principios y reglas que caracterizan al arbitraje. En ese sentido, uno de los principios en el que se fundamenta el DLA, en concordancia con la Ley Modelo de la CNUDMI/UNC1TRAL, es el de gozar de única instancia. Por ello, el clásico recurso impugnatorio de apelación sea improcedente en el arbitraje. En esa misma línea, el Tribunal Constitucional en el Exp. 01755-2007-PA/TC (en adelante "caso El Molino de Cajamarca") ha reconocido que en el arbitraje no existe pluralidad de instancia, señalando que:

"(...) además del derecho a ser juzgado por un juez predeterminado por la ley, cuya renuncia es ínsita a la decisión de someterse a un tribunal arbitral, otra de las garantías formales del debido proceso a las que se renuncia con dicha decisión lo constituye el derecho a la pluralidad de instancias, cuya titularidad y ejercicio está previsto solo para el caso de las personas que deciden someter sus diferencias ante el Poder Judicial $(\ldots)^{\prime \prime 22}$.

Por otra parte, tal como indica el artículo $8^{\circ}$ del DLA "la Sala Civil Subespecializada en lo Comercial o, en su defecto, las Sala Civil de la Corte Superior de Justicia del lugar del arbitraje ", será la competente para resolver el recurso de anulación. Sobre ello, es importante sostener que en estos años la conducta del Poder Judicial ha sido acorde al DLA, pues solo se ha centrado en analizar si el laudo cae en algunas de las causales del artículo $63^{\circ}$ para declarar su nulidad. Por tanto, se podría decir que el órgano estatal de justicia ha actuado conforme al artículo $62^{\circ}$ inc. 2 del DLA, el cual regula:

"(...) está prohibido bajo responsabilidad, pronunciarse sobre el fondo de la controversia o sobre el contenido de la decisión o calificar los criterios, motivaciones o interpretaciones expuestas por el tribunal arbitral $(\ldots)^{\prime \prime}$

A pesar de eso, la parte que no logra un laudo arbitral a su favor -al ver que en el Poder Judicial desestiman sus pretensiones- utiliza el recurso de anulación como 
una vía que debe agotar para ir a un proceso constitucional de amparo. Así, la parte vencida busca ir al amparo con el argumento de una supuesta vulneración a la tutela procesal efectiva, con frecuencia al debido proceso, con el único objeto de lograr -de manera indirectauna nueva valoración sobre el caso que lleve a la inminente declaración de nulidad del laudo emitido.

Si bien esta inadecuada conducta de la parte vencida es un problema que subsiste en todo tipo de procesos, pues es común utilizar todos los medios impugnatorios que estén al alcance para cambiar una decisión que no es favorable, el tema es preocupante cuando el propio Tribunal Constitucional realiza un análisis inadecuado de instituciones que involucran al arbitraje. Así, en el Exp. 05311-2007PA/TC, el Tribunal ingresó a analizar el fondo del laudo emitido, fungiendo de una segunda instancia y en contradicción con la normatividad del DLA y su propio pronunciamiento en el caso Molino de Cajamarca. Por ende, el Tribunal vulnera la voluntad de las partes, cuando ellas a través del convenio arbitral han decidido que sus controversias serán resueltas en única instancia y de forma exclusiva por los árbitros, situación que contradice una de las principales ventajas de este medio alternativo frente al Poder Judicial: el resolver las controversias con celeridad mediante un solo pronunciamiento.

Este punto es apenas una muestra de la equivocada actuación del Tribunal, reflejo del desconocimiento de la normatividad arbitral que perjudica gravemente a un medio alterno de solución de controversias como el arbitraje, ya que producto de ello en algunos casos se está declarando la nulidad de laudos arbitrales, afectando a la parte vencedora en el arbitraje, la cual ha optado por esta vía al considerarlo un medio más atractivo que el Poder Judicial. En esa línea, el propio Tribunal Constitucional está difundiendo la mala utilización del amparo, incentivando indirectamente a que la parte que no fue favorecida por el laudo busque la nulidad del laudo y hasta tal vez obtener un nuevo pronunciamiento sobre el fondo, el cual deberá ser emitido por los árbitros en concordancia con lo resuelto por el Tribunal.

\section{REFLEXIÓN FINAL}

La libertad de las partes provoca que estas voluntariamente lleguen a celebrar el convenio arbitral, por el cual someten la resolución de sus controversias a decisión exclusiva de los árbitros. Solo ellos se podrán pronunciar sobre el fondo de la controversia. debiendo existir un único laudo, sin posibilidad de control sobre el fondo, por lo que, es improcedente el recurso de apelación, admisible en el proceso civil ante el Poder Judicial.

Con el objeto de controlar la legalidad del proceso arbitral, se permite la intervención judicial de manera ex post a la emisión del laudo. Así, se puede interponer el recurso de anulación, pero solo después de emitida la decisión final, la cual procederá para una revisión formal del laudo en los casos que ocurra alguno de los supuestos del artículo $63^{\circ}$ del DLA (incluido la Duodécima Disposición Complementaria).

Hoy el real problema del arbitraje ocurre luego de la emisión del laudo arbitral, ya que la parte vencida utiliza el recurso de anulación con el fin de lograr una nueva valoración sobre el caso; sin embargo, al limitarse la Corte Superior a analizar la existencia de los supuestos de anulación, se ha generado que las partes recurran constantemente al proceso constitucional de amparo, argumentando supuestas vulne- 
raciones a la tutela procesal efectiva y, con ello, al debido proceso, con el único objeto de que se declare la nulidad del laudo.

En consecuencia, se invoca a los jueces constitucionales, el análisis minucioso de un proceso de amparo contra un laudo arbitral, ya que es frecuente su mala utilización, con el objeto de buscar un segundo pronunciamiento sobre el fondo, pese a la existencia de un convenio arbitral, por el cual las partes se someten a las reglas y principios de un medio heterocompositivo de resolución de controversias como el arbitraje. 